it attenuated the perception of social exclusion and loneliness, by reviving the feeling of usefulness and social inclusion, by providing a real life experience and by meeting the needs of this phase of life. The possibility of self-expression also favored the maturation and psychosocial development of children, as the correspondence produced an interlocutor that listened carefully and sought to understand the demands that are specific to childhood.

\section{EXPANDING THE VIEW OF MUTUAL BENEFIT TO SUSTAIN INTERGENERATIONAL PROGRAMS \\ R.H. Weaver ${ }^{2}$, J. Naar ${ }^{2}$, S.E. Jarrott ${ }^{1}$, 1. College of Social Work, The Ohio State University, Columbus, Ohio, 2. Virginia Tech, Blacksburg, Virginia}

Using content analysis, we identified themes in data collected via small focus groups and individual interviews with staff and administrators $(\mathrm{N}=30)$ from six sites where childcare centers partnered with adult day services, senior center, and elder volunteer programs. As a USDA CYFAR Sustainable Community Project, emergent themes addressed the impact of intergenerational programming on children, elders, families, and staff as well as issues of sustainability. Resources provided by the project, primarily training on best intergenerational practices, were evaluated as contributing to sustainability. Collaborative partnerships that included Extension Educators, also contributed to sustainability. Sites identified different barriers to intergenerational programming, reflecting their financial resources, diverse partners, and buy-in of program stakeholders. Investigators interpret interviewees' responses, conducted over the 5-year project, as reflecting the unique contexts of each program. For example, the longest running intergenerational program was challenged by staff buy-in, which evidenced itself in observations of participants and staff. In contrast, the newest program achieved early buy-in and had AAA and Head Start resources to support their efforts. Findings bolster previous research indicating that effective intergenerational programs must benefit all stakeholders - not just the youth and elder participants. Taking a participatory approach that involves staff, administrators, and participants promotes mutual benefit with program nimbleness. Support from Extension professionals facilitates stronger, denser network connections for partners to draw upon.

\section{GENDERED ALLOCATION OF SUPPORT FOR AGING PARENTS AND PARENTS-IN-LAW IN TAIWAN}

Y. Cheng ${ }^{2}, \mathrm{H} . \mathrm{Ko}^{1}$, 1. Central Michigan University, $\mathrm{M} t$. Pleasant, Michigan, 2. New graduate, Sunnyvale, California

Adult offspring is the main source of support for their older parents. With the aging population increasing worldwide, how married adults allocate their limited resources to their parents and parents-in-law is becoming a major challenge. Based on the U.S. literature, married women tend to provide more support to their own parents than to their parents-in-law. Men follow their wives and help parents-in-law more than their own parents. In contrast, in the Taiwanese traditional culture, married women should allocate resources to parents-in-law rather than to their own parents; married men are not responsible for helping parents-in-law. However, little is known about whether married adults in Taiwan actually follow the traditional support allocation. This study examined married adult offspring's allocation of financial and practical support based on the 2011
Taiwan Social Change Survey. Married adults with at least one parent and parent-in-law living were included $(n=535 ; 48 \%$ women; mean age $=47.25)$. Multilevel models indicated that women allocated more frequent practical support for parentsin-law than for their parents, and gave the same level of financial support to both parents and parents-in-law. Men gave both practical and financial support more frequently to their parents than to parents-in-law. In general, these findings fitted the Taiwanese traditional expectation of support allocation, especially for men. Although women still fulfill their obligation to help parents-in-law, they may be more inclined to help their own parents due to their increased participation in the labor force. Implications on policy and gender roles in Taiwan are also discussed.

\section{GRANDPARENTS RAISING GRANDCHILDREN SELF- CARE PRACTICES: THE GRANDCARES PROJECT}

C.A. Fruhauf ${ }^{1}$, L. Yancura $^{2}$, H. Greenwood ${ }^{2}$, A.N. Mendoza ${ }^{1}$, 1. Human Development \& Family Studies, Colorado State University, Fort Collins, Colorado, 2.

University of Hawaii at Manoa, Manoa, Hawaii

Globally, it is well known that grandparents often serve their families by providing instrumental and emotional support. Grandparents may also assume the role of "surrogate parent" or raise grandchildren when the middle generation is unavailable. When grandparents assume the primary caregiving role of their grandchildren, they often experience decreases in their physical and mental health. One aspect of health and well-being that is critical to maintaining and improving optimal health in later life is self-care. Self-care focuses on personal health maintenance and includes positive lifestyle practices. Despite the self-care literature being rooted in the medical field with more than 25,000 articles on the topic, empirical research addressing grandparents' raising grandchildren selfcare practices, however, is minimal. Furthermore, although chronic disease self-management interventions are well known, until recently, no program directly targets self-care practices of grandparents. As a result, we utilized methods in communitybased participatory research (CBPR), which is often used to identify and meet the needs of at-risk populations, to develop and implement The GRANDcares Project. This presentation will extend the literature on CBPR principles by describing our collaborative working relationships with local and state agencies, including two statewide Extension systems, serving grandparent caregivers. We also will address our research objectives and outcomes related to improving grandparents' self-care. Finally, we will address the theoretical background of CBPR, the challenges and benefits of using CBPR as a recruitment and retention strategy, and suggest guidelines for using this method to support self-care practices of grandparent caregivers in both the United States and abroad.

\section{APPLICATION OF INTERGROUP CONTACT THEORY TO MANAGING AGE-DIVERSE TEAMS}

M. Choi ${ }^{1}$, S.E. Jarrott ${ }^{1}$, J. Naar ${ }^{2}$, 1. Social Work, The

Obio State University, Columbus, Ohio, 2. Virginia Tech, Blacksburg, Virginia

The outcomes of different generations working together can be mixed. Previous literature has taken a pessimistic view, addressing conflict and social categorization among 
generations. Alternatively, we consider an optimistic view, using contact theory to explore employees' perspective on the different career stages as they relate to team effectiveness. Allport identified necessary conditions for positive intergroup contact. Data from the Age and Generations Study were analyzed using Hayes' indirect macro analysis technique, which enables researchers to test multiple mediators in the same model. We examined the mediating effect of attitudes toward different career stages on the direct relationship between supervisor support and team effectiveness and between team inclusion and team effectiveness. Of 1,572 participants, $60.4 \%$ were female and the mean age was 50.30 years $(S D=12.10)$. Results achieved significant mediation models with supervisor support and team inclusion accounting for respectively, $44.3 \%$ and $52.7 \%$ of the adjusted variance. The total and direct effects of supervisor support on team effectiveness are $0.50, p<.001$, and $0.43, p<.001$, respectively. Additionally, the total and direct effects of team inclusion on team effectiveness are $0.55, p<.001$, and $0.50, p<.001$, respectively. Our findings reflect the value of contact theory tenets of authority support and cooperation towards a common goal in supporting successful outcomes of diverse team. Future efforts should explore strategies to optimize supervisor support and enhance team engagement. Improving attitudes toward the out group in age-diverse teams may be key to reducing potential conflict in age-diverse workplaces.

\section{THE EFFECTS OF AN INTERGENERATIONAL SERVICE LEARNING EXPERIENCE ON AGEIST ATTITUDES}

K. Ivey ${ }^{1,2}$, D.C. Potts ${ }^{1,2,3}$, S. Gately ${ }^{1,2}$, J. Westmoreland ${ }^{1,2}$, H. Henkin ${ }^{1,2}$, E. Mayer ${ }^{1,2}$, A. Halli-Tierney ${ }^{1,2}$, R.S. Allen ${ }^{1,2}$, 1. Psychology, University of Alabama, Tuscaloosa, Alabama, 2. Alabama Research Institute on Aging, Tuscaloosa, Alabama, 3. Cognitive Dynamics, Tuscaloosa, Alabama

Intergenerational service learning programs address ageist attitudes by bolstering empathetic intergenerational relationships, creating a comprehensive, realistic view of aging, and fostering positive attitudes towards older adults. We examined learning outcomes for undergraduate students enrolled in: 1) an experiential, 2) didactic aging content, and 3) introductory psychology courses. Students completed pre- and post- surveys measuring empathy and attitudes toward older adults and persons with dementia (PWD) and community service. Students enrolled in the experiential course exhibited improved attitudes towards PWD, Wilks' lambda $=0.952$, $\mathrm{F}(2,355)=8.98, \mathrm{p}<.0001(M=14.25, S D=.36)$ relative to students in psychology of aging $(M=12.59, S D=.17)$ or PY $101(M=11.87, S D=.12)$. Moreover, attitudes towards community service were improved for students enrolled in the experiential course, Wilks' lambda $=.502$, $\mathrm{F}(2,356)=176.436, \mathrm{p}=.000(M=27.71, S D=.41)$ relative to students in psychology of aging $(M=25.29, S D=.19)$ or PY $101(M=22.160, S D=.13)$. Finally, students in the experiential course showed greater increases in empathy, Wilks' lambda $=.856, \mathrm{~F}(2,345)=29.058, \mathrm{p}=.000(M=47.52$, $S D=.75)$ relative to students in psychology of aging $(M=44.10, S D=.34)$ or PY $101(M=41.52, S D=.22)$. Intergenerational service learning courses may offer a sustainable avenue for delivery of interventions to PWD in the community and facilitate entry of students into professions in geriatrics and gerontology.

\section{WE WILL NOT BE MOVED: ELDERLY PERSONS' RESILIENCE IN FRONTIER LOCATIONS IN OPERATION PROTECTIVE EDGE}

I. Regev, O. Nuttman-Shwartz, Sapir academic college, Sderot, Israel

The unique ways of coping of elderly people during times of threat are examined here. The population were elderly Israelis who chose to remain in their frontier-location homes during Operation Protective Edge in the summer of 2014. Three semi-structured focus groups were held in three different locations, in September and October, 2014. Each three-hour group discussion included introductions and a conversation about the war and coping with it. An open question invited participants to tell their personal story of the operation. Content-categorical analysis of the transcripts yielded four main themes: (1) Together - ethical theme: individual vs. collective, worry about oneself vs. worrying about others; (2) I'm not afraid - emotional theme: expressing emotions that vacillated between lack of fear to fear, loneliness, failure, desertion vs. courage, uncertainly, anger and disappointment with the state and the army, pain, and bad conscious; (3) Glad the kids left - intergenerational theme: different generational perspectives of the operation and means of coping, and issues of continuity and faith in the ways of the kibbutz/community vs. the possibility of leaving; (4) We will not be moved - personal and communal resilience theme, personal vs. communal responsibility. The many elderly residents who remained at home during the operation raised personal, familial, ethical, and communal issues and dilemmas, which can be explained by (1) the developmental stage of the elderly people, (2) processes of change in the kibbutz/community, and (3) different coping patterns resulting from generational differences.

\section{THE ACTUAL AND EXPECTED AVAILABILITY OF INFORMAL CARE: CHILDLESS ELDERLY PEOPLE AND PARENTS}

M. Kohli ${ }^{1}$, M. Albertini ${ }^{2}$, 1. SPS, European University

Institute, Berlin, Germany, 2. University of Bologna, Bologna, Italy

As people get older, they face the question of who will provide them with care if they ever need it. Current estimates indicate that approximately $87 \%$ of Americans who receive long-term care receive it from informal caregivers. However, the supply of family caregivers is unlikely to keep pace with future demand, and increasing childlessness rates represent an additional challenge. Using data from the HRS, the present study analyzes how childlessness affects the probability that disabled individuals receive informal care, and nondisabled individuals anticipate future informal care. In contrast to most previous research, the childless are not treated as an homogeneous group; different types of and pathways to childlessness are distinguished. In general, the results do not hold up the claim that in the US non-parents face significant support deficits in old age. The probability of receiving support is substantially lower only for those who survived their children, whereas the weak negative effect observed for those who never had natural nor step-children is not statistically significant. Compared to natural parents, step-parents receive more support from their partners but get less help from their children. The analysis of support expectations 